\title{
KNOWLEDGE AND COMPETENCE OF AGRICULTURAL EXTENSION FIELD WORKERS IN FARMER-GROUP FACILITATION IN KWARA STATE, NIGERIA
}

\author{
Kemi Funmilayo Omotesho ${ }^{1}$, Blessing Akinola-Soji², \\ Gbolagade Benjamin Adesiji¹, Oluwasanjo Biodun Owojaiye ${ }^{3}$
}

\footnotetext{
${ }^{1}$ Department of Agricultural Extension and Rural Development, University of Ilorin, University of Ilorin Permanent site, Tanke, Ilorin, Kwara State, Nigeria

${ }^{2}$ Nigerian Stored Product Research Institute, Asa Dam Road, Ilorin, Kwara State, Nigeria

${ }^{3}$ Landmark University, Omu Aran, Kwara State, Nigeria
}

Link to this article: https://doi.org/10.11118/actaun.2021.020

Received: 13. 6. 2020, Accepted: 26. 2. 2021

To cite this article: OMOTESHO KEMI FUNMILAYO, AKINOLA-SOJI BLESSING, ADESIJI GBOLAGADE BENJAMIN, OWOJAIYE OLUWASANJO BIODUN. 2021. Knowledge and Competence of Agricultural Extension Field Workers in Farmer-Group Facilitation in Kwara State, Nigeria. Acta Universitatis Agriculturae et Silviculturae Mendelianae Brunensis, 69(2): 231-239.

\begin{abstract}
The weakness of most farmer-groups in Nigeria has been linked to poor group facilitation by field agricultural extension workers. The study assessed the knowledge and competence of extension officers in group facilitation. A two-stage random sampling technique was used to select 174 farmers on which a structured interview schedule was administered. A questionnaire was administered on all 69 field extension workers in the study area. Descriptive statistics, regression analysis, Pearson's Product Moment Correlation and t-test were used for data analyses. Results reveal that $65.2 \%$ of extension workers had good knowledge of group facilitation. Farmers rated extension workers lower (mean $=2.36$ ) than the workers rated themselves in group facilitation (means $=3.12$ ). Work experience of extension workers and their access to training in group dynamics significantly influenced workers' competence at $\mathrm{P}<0.05$. There was a significant relationship between the knowledge and competence of extension workers at $p<0.05(r=0.843)$. The study assessed extension workers' competence in group facilitation using both self and farmers' assessments, identifying specific areas of deficiencies in knowledge and competence.
\end{abstract}

Keywords: competence, knowledge, group dynamics, group facilitation, self-assessment

\section{INTRODUCTION}

Some factors underscore the need for vibrant farmer-groups in developing countries with large numbers of small-scale resource-poor farmers. In Nigeria, for instance, the abysmally low extension agent-to-farmer ratio makes the delivery of extension services through groups a necessity. The much advocated demand-driven approach (and indeed all participatory approaches) to extension requires that extension service delivery is done through organised farmer-groups. These groups can also complement the effort of extension organisations by providing extension services to their members via an expansion of the farmer-tofarmer information systems. Also, the reliance of international donor agencies and other development partners on farmer-groups as the medium of reaching small-scale farmers is a justification for the strengthening of the groups. Membership of 
farmers' associations offers advantages such as the benefits of economies of scale through joint purchases and collective bargaining. It can also aid the adoption of innovation through joint ownership of technologies that individual farmers may not be able to afford. However, despite these and other advantages of farmer-groups, their performances remain very poor.

Low membership, poor participation, weak leadership, and inactivity are some of the severe challenges to farmer-groups in Nigeria (Omotesho et al., 2016). Many "registered" farmer associations exist only on paper while some are only ad-hoc groups hurriedly put together for specific developmental programmes. The process and purpose of formation of some of the groups assure their eventual failure. It is expected that to contribute meaningfully to sustainable agricultural development, these groups should have the capacity to meet their goals and serve the needs of members (Abaru et al., 2006). For groups to be effective, farmers need to be well organised (Bosc et al., 2002). Groups should have the capacity to deliver relevant services which allows smallholder farmers to participate actively in collective action at the grass-root level (Mukindia, 2014). Facilitating the formation and success of farmer-groups is one of the roles of extension organisations. The scope of agricultural extension services has been widening, and the need to adapt to changing contexts is also growing.

The strategies of agricultural extension have since changed over the years. There has been a paradigm movement from the conventional extension tactics such as teaching and decision making for farmers, to the facilitation of farmers to achieve their goals by themselves. For instance, farmers now identify their needs themselves while the extension worker merely facilitates the process without interfering in the outcomes of such processes. Tools such as farmers' focus group discussion and innovative platforms are now being promoted and adopted with significant effect in the pursuit of agricultural development. This shift brings to fore, the importance of the facilitation skills of agricultural field extension workers. Suvedi and Ghimire (2015) opined that the role of extension today transcends technology transfer to facilitation and beyond training to learning. It also includes assisting farmers in forming groups, dealing with marketing issues, addressing public interest issues in rural areas and partnering with a broad range of service providers and other agencies in rural development.

In a developing country like Nigeria, rural people exclusively depend on extension officers for technical advice and information. The success of any extension program will be determined to a great extent by the ability of her extension staff to display competence since the entire extension delivery process depends on them to transfer innovation and technical advice to the rural people (Owen, 2004). Also, the productivity of the extension organisation highly depends on the function of extension officers. As such, competent and knowledgeable extension personnel will ensure the success of the extension service and agricultural development programmes.

Extension organisations are expected to attain sustainable agricultural development and take part in coordinating and leadership roles among agricultural stakeholders (Rajalahti, 2012). This means that extension organisations must understand and adjust to swift changes and emerging challenges in order to succeed (Extension Committee on Organisational Policy, 2002). Suvedi and Ghimire (2015) noted that extension professionals were now judged based on how they provide for their clientele; whether they demonstrate empathy and communicate effectively with their clientele, how their relationship is with their clientele and how conversant they are with their clienteles' contexts and concerns. As a result of these demands, Moore (2015) opined that extension experts should have mastery of several non-technical or procedure skills, such as; communication skills, critical thinking, teamwork, entrepreneurship and leadership as well as practical capacities to enable them to function effectively in their service delivery. Agricultural extension contributes to improving the wellbeing of farmers and other stakeholders by providing access to knowledge and information. This has resulted in increased emphasis on the development of core competencies which are necessary for the extension personnel to perform at maximum and produce expected results in service delivery.

Issahaku (2014), defined competency as a skill, a personal characteristic, or a motive demonstrated by various behaviors which contribute to outstanding performance in a job. It is the quality of being adequately or well qualified, having the ability to perform a specified task. Competency assessment is designed to evaluate individual knowledge, education, skills, experience, and proficiency to perform those assigned responsibilities (Herringer, 2002). The identification of key competencies provides for personal and organisational growth and helps the organisation meet future demands. Therefore, focusing on competencies will help an organisation to outline the responsibilities, knowledge, and skills required by their employees for a particular position. Therefore, because professional competencies are essential to perform jobs well, extension organisations expect their employees to use specific professional tools to help their clientele and achieve desired results. Also, for the extension workers to fully meet the needs of the smallholder farmers, they have to acquire the right knowledge. Furthermore, the success of extension workers in empowering and establishing farmergroups is determined by various factors, especially factors (such as characteristics, independence, and social system) that will influence the motivation and competence of the extension workers. 
Unfortunately, the knowledge and competence of extension personnel, particularly in farmergroup facilitation, has been quarried as a result of the poor performances of the groups. While there is the dearth of empirical information on the extension workers' knowledge of facilitation, the few studies on their competence have not explicitly focused on facilitation skills, Also most studies in this area have relied only on self-assessment by the extension workers. The crucial assessment by the beneficiaries (farmers) has not been carried out. It is essential to make a comparison between both assessments. An understanding of the influence of extension workers' socio-economic characteristics on their level of competence will also help in addressing their competency challenges. Finally, it is possible that extension workers face some constraints in the discharge of this assignment. Based on this background, the following objectives and hypotheses were formulated to guide the study; 1. To assess the knowledge level of extension workers in farmer-group facilitation.

2. To assess the extension workers' competence in farmer-group facilitation.

The hypotheses of the study were stated in the null form as follows:

$\mathrm{HO}_{1}$ : Socio-economic characteristics of field extension workers do not affect their competence level.

$\mathrm{HO}_{2}$ : There is no significant relationship between field extension workers' knowledge and their competence in group facilitation.

$\mathrm{HO}_{3}$ : There is no significant difference between field extension workers' and farmers' assessment of the competence of extension workers in groupfacilitation.

\section{MATERIALS AND METHODS}

\section{Study Area}

The study was conducted in Kwara State of Nigeria. Located in North-Central, Nigeria, the state has a landmass of 36,825 square kilometres and has a population of 3.49 million (Projected from 2006 census figure). Kwara State is subdivided into four zones by the Kwara State Agricultural Development Project (KWADP) in consonance with ecological characteristics, cultural practices and for the projects' administrative convenience. Agricultural extension in the state is mainly public and administered by the Kwara State Ministry of Agriculture. The state has an estimated figure of 524,837 farm families, the majority of which live in the rural areas (International Fund for Agricultural Development IFAD, 2012). There are over 700 registered rural groups in the state, majority of which are economic interest groups. The groups are segregated into various crop farming groups, processor groups, various forms of animal husbandry groups and the vulnerable groups.

\section{Sampling Procedure and Sample Size}

The population for the study comprised all field extension workers and members of all cropbased farmer-groups in Kwara State. The sample size consisted of all 69 field extension workers in Kwara State and 174 farmers drawn from the list of farmer-groups in the state. A two-stage sampling procedure was used in the selection of farmers. A random selection of $50 \%$ of the 116 registered crop-based farmer-groups in the state was made in the first stage. Secondly, three farmers each were randomly selected from the 58 selected groups making a total of 174 farmers. The total sample size used in the study was 243.

\section{Data Collection and Analysis}

The instruments for data collection were a questionnaire (for extension workers) and an interview schedule (for farmers). Descriptive statistics were used to report the results of all the specific objectives of the study. The knowledge level of extension officers was measured using a knowledge test, the teacher-made test (Meena et al., 2012). This involved the development of a comprehensive list of 20 questions which when pulled together, reflects the knowledge of extension workers in group facilitation. The scoring guide was one (1) score for each correct answer and Zero (0) score otherwise. A score of 15 out of 20 (75\%) was adopted as benchmark for the possession of a good level of knowledge in group facilitation. Scores of between 10 and 14.9 (50\%-74.9\%) were categorised as fair, while scores below $10(<50 \%)$ were categorised as poor. The level of competence was measured using a 4-point Likert scale. A Likert-type scale was used to assess the severity of constraints to group facilitation. Regression analysis, Pearson's Product Moment Correlation (PPMC) and t-test analysis were used to test the hypotheses of the study.

\section{RESULTS AND DISCUSSION}

\section{Socio-Economic Characteristics of Field Extension Workers}

This section presents results and discussion on the selected socio-economic characteristics of the field extension workers in the study area. Tab. I shows the socio-economic characteristics of field extension workers.

As shown in Tab. I, 33.3\% of the extension workers belonged to the age bracket $21-40$ years, while $66.7 \%$ fell between 41 and 60 years of age, with a mean of 50 years. Also, 78.3\% of the field extension officers were male, implying that male extension workers were in the majority compared to their female counterparts. This is in tandem with the report of Swanson et al. (1992) that female extension agents were generally fewer in most parts of the world. The majority (95.6\%) were married 
I: Socio-economic characteristic of field extension workers $(n=67)$

\begin{tabular}{|c|c|c|c|c|}
\hline Variable & Frequency & Percentage & Mean & SD \\
\hline \multicolumn{5}{|c|}{ Age (Years) } \\
\hline $21-40$ & 23 & 33.3 & 50.23 & 12.71 \\
\hline $41-60$ & 46 & 66.7 & & \\
\hline \multicolumn{5}{|c|}{ Marital Status } \\
\hline Single & 3 & 4.4 & & \\
\hline Married & 66 & 95.6 & & \\
\hline \multicolumn{5}{|c|}{ Sex } \\
\hline Male & 54 & 78.3 & & \\
\hline Female & 15 & 21.7 & & \\
\hline \multicolumn{5}{|c|}{ Level of Education } \\
\hline Secondary & 1 & 1.4 & & \\
\hline Tertiary & 68 & 98.6 & & \\
\hline \multicolumn{5}{|c|}{ Working Experience (Years) } \\
\hline$\leq 10$ & 21 & 30.4 & & \\
\hline $11-20$ & 30 & 43.5 & 15.45 & 5.23 \\
\hline$\geq 21$ & 18 & 26.1 & & \\
\hline \multicolumn{5}{|c|}{ Access to training } \\
\hline Yes & 44 & 63.8 & & \\
\hline No & 25 & 36.2 & & \\
\hline
\end{tabular}

Source: Field Survey, 2019

and had tertiary education (98.6\%). This is contrary to the belief in Nigeria that extension job is a lowstatus job fit only for job applicants possessing low academic qualifications (Ejembi et al., 2006). This result indicates a high level of education of the extension workforce compared to what existed a few decades ago. This is significant, giving the level of technological advancement in agriculture, ever-increasing challenges in farming system and corresponding changes in the knowledge structure of the agriculture/rural labour.

Furthermore, $30.4 \%$ of the respondents had working experiences of between one (1) and ten (10) years in extension work, $43.5 \%$ had 11 to 20 years of experience while $26.1 \%$ of the respondents had at least 21 years of experience in extension work. It is logical to expect that the longer a person is in any business or profession, the more skilled and experienced they become in its management. Furthermore, $63.8 \%$ had undergone some training in group dynamics, while $36.2 \%$ had no training in group dynamics.

\section{Field Extension Workers' Knowledge in Farmer-Group Facilitation}

The result of the assessment of the extension worker's knowledge in farmer-group facilitation is presented and discussed in this section. Tab. II shows the performance of the extension workers by knowledge questions used in the survey.

As shown in Tab. II, the knowledge statements/ questions revolved around the importance of group facilitation, the qualities expected of a good facilitator and the scope of group facilitation. The respondents correctly answered most of the questions on the importance/benefits of facilitation and qualities expected of a group facilitator. The extension workers, however, performed poorly in the questions relating to the scope of facilitation. For instance, the lowest mean score (8.7\%) was recorded in the statement that defined the role of extension workers as facilitators in solving credit needs of farmer-groups. Answers provided show that the extension workers thought their roles went beyond linkage with credit sources to becoming involved in the actual provision of credit. In addition, the mean score of $14.5 \%$ for the question on the involvement of extension workers in farmer-group leadership also reveals that they had poor knowledge of the scope of their role of group-facilitation. The overall performance of the extension workers in the knowledge test is summarised in Tab. III.

Tab. III shows that $65.2 \%$ of the extension workers had a good knowledge level of group facilitation, while $34.8 \%$ had an only fair knowledge of group facilitation. With an overall mean score of 15.15, the result indicates that field extension workers' knowledge of group facilitation was generally good but had room for improvement. These results corroborate the findings of Ramdwar et al. (2015) positing that extension workers had the technical knowledge needed to service farmers' groups appropriately.

\section{Field Extension Workers' Competence in Group Facilitation}

This section discusses the competence of extension workers in group facilitation. Tab. IV to VII presents a summary of the extension workers' self-assessment and farmers' assessments of the extension workers' competence.

\section{Self-assessment}

According to results on Tab. IV, the extension workers rated themselves highly competent in 13 out of the 20 areas listed. These areas include recording and reporting $(\mathrm{MS}=3.62)$ ranked $1^{\text {st }}$, Leadership skills $\left(\mathrm{MS}=3.35\right.$ ) ranked $2^{\text {nd }}$, and interpersonal communication skills $(\mathrm{MS}=3.32)$ ranked $3^{\text {rd }}$. The table also reveals field extension officers had good competence in communication skills, group formation, a good understanding of people and culture, effective time management, conflict resolution, setting program priorities/decision skills, and recognizing learning difference in age group. This result corroborates that of Chikaire et al. (2018) who reported high competence of field extension works in leadership skills, program priority 


\begin{tabular}{|c|c|}
\hline Agricultural extension can and should play a facilitation role in the farmer-group formation. & 100.0 \\
\hline $\begin{array}{l}\text { Group facilitation role of extension agent can enhance disseminating information and technologies } \\
\text { on Agricultural development. }\end{array}$ & 100.0 \\
\hline While the group focuses on the task, the extension agent focuses not only on the process but also on the people. & 98.6 \\
\hline Extension agent should never impose a solution (decisions) on farmer-groups. & 98.6 \\
\hline $\begin{array}{l}\text { Facilitation by extension agent for the farmer-groups is a crucial strategy adopted for generating demand for } \\
\text { agricultural extension services. }\end{array}$ & 98.6 \\
\hline For effective functioning of farmer-groups, extension agents must act as a facilitator rather than an expert. & 97.1 \\
\hline Expertly facilitated farmer-groups produce higher quality work and build a broader base for timely implementation. & 97.1 \\
\hline $\begin{array}{l}\text { An extension agent helps the group stay focused on its tasks, explore situation more fully, minimize } \\
\text { interpersonal conflict unrelated to work. }\end{array}$ & 94.2 \\
\hline Ability to actively listen is an important communication skill and required for group facilitation. & 92.8 \\
\hline $\begin{array}{l}\text { Group facilitation does not encourage the improvement of adoption of technologies due to the level } \\
\text { of education of members of the group. }\end{array}$ & 79.9 \\
\hline
\end{tabular}

Dynamics of any group is highly complex. Is it essential for extension agent to understand dynamism within the group he manages.

Group facilitation reduces the group dynamics to achieve improvement of member's welfare.

There is provision for review and comments about group facilitation issues by the government extension agencies.

Extension agents ensure participation of all members; however, paraphrasing individuals contribution, maximizing learning and encouraging passive participant are not his roles.

The process used in identifying priorities, making decisions and solving problems in a group setting is the same as when dealing with individual farmers.

The effectiveness of extension agents in facilitation involves providing leadership and also taking the rein.
Group facilitation involves extension agents providing credit facilities to the farmer-groups on his terms when none is forthcoming from Government or other agencies.

Source: Field Survey, 2019; KS (Knowledge score)

III: Distribution of field extension workers by their scores in the knowledge test $(n=67)$

\begin{tabular}{lccc}
\hline \multicolumn{1}{c}{ Knowledge Level } & Frequency & Percentage & Mean \\
\hline Poor $(<10)$ & 0 & 0 & \\
Fair $(10-14)$ & 24 & 34.8 & 15.15 \\
Good $(\geq 15)$ & 55 & 65.2 & \\
\hline
\end{tabular}

Source: Field Survey, 2019

planning, communication skills, project management, education \& informational technology. Group management, provision of feedback, and visualising problems/prospects were the skills in which the extension workers rated themselves the lowest.

Tab. V provides a summary of the individual scores of the extension workers. Results in Tab. V reveal that most of the respondents $(78.3 \%)$ rated themselves high in competence on group facilitation.
Few (21.7\%) indicated a fair level of competence in group facilitation. With a mean competence score of 3.12 from a total obtainable score of four, the result indicates a high level of competence in group facilitation among the field extension workers and also reveal opportunity for an improvement in the competence level of the workers. Nwaogu and Akinbile (2018) also reported similar findings.

\section{Farmers' Assessment}

The result of farmers' assessment of the competence of extension workers in group facilitation is summarised in Tab. VI. The table reveals that farmers rated field extension workers most competent in the training of farmers (MS = 3.46). The farmers also rated the workers to be highly competent in good understanding of people and culture as well as displaying leadership skills. Other group facilitation skills in order of competence included; recording and 
IV: Extension officers' assessment of their competence in group facilitation

\begin{tabular}{|c|c|c|c|c|c|c|}
\hline Task & $\begin{array}{c}\text { Very Poor } \\
\text { F (\%) }\end{array}$ & $\begin{array}{l}\text { Poor } \\
\text { F (\%) }\end{array}$ & $\begin{array}{l}\text { Good } \\
\text { F (\%) }\end{array}$ & $\begin{array}{c}\text { Very Good } \\
\text { F (\%) }\end{array}$ & Score & MS \\
\hline Recording and Reporting & $0(0)$ & $0(0)$ & $26(37.7)$ & 43(62.3) & 250 & 3.62 \\
\hline Leadership skills & 1(1.4) & $0(0)$ & $42(60.9)$ & 26(37.7) & 231 & 3.35 \\
\hline Interpersonal communication Skill & $0(0)$ & $0(0)$ & $47(62.7)$ & $22(31.9)$ & 229 & 3.32 \\
\hline Group formation & $0(0)$ & $0(0)$ & 48(69.6) & 21(30.4) & 228 & 3.30 \\
\hline Effective Time management & $0(0)$ & $0(0)$ & $50(72.5)$ & 19(27.5) & 226 & 3.28 \\
\hline Conflict Resolution & $0(0)$ & $1(1.4)$ & 48(69.6) & 20(29.0) & 226 & 3.28 \\
\hline Setting program priorities/decision making skills & $0(0)$ & $0(0)$ & $51(73.9)$ & 18(26.1) & 225 & 3.26 \\
\hline Good understanding of people and culture & $0(0)$ & $1(1.4)$ & $49(71.0)$ & 19(27.5) & 225 & 3.26 \\
\hline Recognizing learning difference in age group & $0(0)$ & 1(1.4) & $50(72.5)$ & 18(26.1) & 224 & 3.24 \\
\hline Participating Monitoring and Evaluating group programs & $0(0)$ & $0(0)$ & $56(84.2)$ & 13(18.8) & 220 & 3.19 \\
\hline Farmers Training & $0(0)$ & $0(0)$ & $56(84.1)$ & 13(18.8) & 220 & 3.19 \\
\hline Extension Education and teaching & $0(0)$ & $0(0)$ & $56(84.1)$ & 13(18.8) & 220 & 3.19 \\
\hline Driving participation & $0(0)$ & $0(0)$ & $58(84.1)$ & 11(15.9) & 218 & 3.16 \\
\hline Selection/Mobilisation of farmer group & $0(0)$ & $14(20.3)$ & $44(63.8)$ & 11(15.9) & 204 & 2.96 \\
\hline Group motivation & $0(0)$ & 13(18.8) & $50(72.5)$ & $6(8.7)$ & 200 & 2.90 \\
\hline Adult Teaching & $0(0)$ & 13(18.8) & $50(72.5)$ & $6(8.7)$ & 200 & 2.90 \\
\hline Problem identification and solution & $0(0)$ & 19(27.5) & $40(57.9)$ & 10(14.5) & 198 & 2.87 \\
\hline Visualise future problems and prospect & $2(2.8)$ & 17(24.6) & $40(57.9)$ & $10(14.5)$ & 196 & 2.84 \\
\hline Group management & $2(2.8)$ & 17(24.6) & 40(57.9) & 10(14.5) & 196 & 2.84 \\
\hline Feedback on programs & $2(2.8)$ & $17(24.6)$ & 40(57.9) & $10(14.5)$ & 196 & 2.84 \\
\hline
\end{tabular}

Source: Field survey, 2019

V: Distribution of field extension workers based on their assessment of their competence level in group facilitation

\begin{tabular}{lccc}
\hline Competence Level & Frequency & Percentage & Mean \\
\hline Low (1.00-1.99) & 0 & 0 & \\
Moderate (2.00-3.00) & 15 & 21.7 & 3.12 \\
High (> 3.00) & 54 & 78.3 & \\
\hline
\end{tabular}

Source: Field Survey, 2019

reporting (MS = 3.29), selection/mobilisation of farmer group (MS = 3.27), extension education and teaching (MS = 3.32) and adult teaching (MS = 3.15). Similar to the result of the assessment by the extension workers, the farmers also rated the extension workers low in group motivation, problem identification and solution, visualising future problems, group management and provision of feedback to groups.

Tab. VII presents a summary of the farmers' perception of the workers' competence. It reveals that only $31.6 \%$ of the farmers rated the extension workers highly competent in group facilitation. While $41.4 \%$ rated them fair, $27 \%$ of the farmers were of the opinion that the extension workers had low competence in facilitation. The overall mean competence score of 2.36 is lower than the mean of the rating by the extension workers (3.12). Sharma et al. (2016) opined that while self-assessment has the potential to identify gaps, motivate, and increase performance, it could result in inflated scores as objectivity is often difficult.

\section{Determinants of Field Extension Workers' Competence Level in Group Facilitation}

Tab. VIII shows the result of regression analysis to identify the determinants of the competence level of field extension workers on group facilitation.

The regression model with five (5) predictors produced an $\mathrm{R}^{2}$ value of $0.429, \mathrm{P}<0.05$. The result reveals that the working experience of extension workers ( $\beta=-0.117)$ and extension workers' access to training in group dynamics ( $\beta=0.214$ ) were the determinants of extension workers' competence level in group facilitation and explained $42.9 \%$ of the variation in the workers' competence. The negative influence of working experience on the competence level of extension workers in group facilitation implies that extension workers with more years of working experience had lower competence. This could be as a result of the extension induction training given to new extension personnel by the extension organisation. It is also possible that the 
VI: Farmers assessment of field extension workers' competence in group facilitation

\begin{tabular}{|c|c|c|c|c|c|c|}
\hline Task & $\begin{array}{c}\text { Very Poor } \\
\text { F (\%) }\end{array}$ & $\begin{array}{l}\text { Poor } \\
\text { F (\%) }\end{array}$ & $\begin{array}{l}\text { Good } \\
\text { F (\%) }\end{array}$ & $\begin{array}{c}\text { Very Good } \\
\text { F (\%) }\end{array}$ & Score & MS \\
\hline Farmers Training & $0(0)$ & $1(0.6)$ & $92(52.8)$ & $81(46.6)$ & 602 & 3.46 \\
\hline Leadership skills & $0(0)$ & $3(1.7)$ & 108(62.1) & 63(36.2) & 582 & 3.34 \\
\hline Good understanding of people and culture & $0(0)$ & $11(6.3)$ & $98(56.3)$ & $65(37.4)$ & 576 & 3.31 \\
\hline Recording and Reporting & $1(0.6)$ & $8(4.6)$ & 105(60.3) & $60(34.5)$ & 572 & 3.29 \\
\hline Selection/Mobilisation of farmer group & $0(0)$ & $5(2.9)$ & 117(67.2) & $52(29.9)$ & 569 & 3.27 \\
\hline Extension Education and teaching & $0(0)$ & $8(4.6)$ & 118(67.8) & $48(27.6)$ & 562 & 3.23 \\
\hline Adult Teaching & $0(0)$ & 21(12.1) & 106(60.9) & $47(27.0)$ & 548 & 3.15 \\
\hline Interpersonal communication Skill & $0(0)$ & $8(4.6)$ & 133(76.4) & 33(19.0) & 547 & 3.14 \\
\hline Driving participation & $0(0)$ & $15(8.6)$ & 120(69.0) & $39(22.4)$ & 546 & 3.14 \\
\hline Group formation & $0(0)$ & 24(13.8) & 111(63.8) & $39(22.4)$ & 537 & 3.09 \\
\hline Participating Monitoring and Evaluating group programs & $0(0)$ & $15(8.6)$ & 130(74.7) & 29(16.7) & 536 & 3.08 \\
\hline Effective Time management & $0(0)$ & $5(2.9)$ & $150(86.2)$ & 19(10.9) & 536 & 3.08 \\
\hline Recognizing learning difference in age group & $0(0)$ & 11(6.3) & 139(79.9) & $24(13.8)$ & 535 & 3.07 \\
\hline Feedback on programs & $37(21.3)$ & 17(9.8) & $100(57.4)$ & 20(11.5) & 451 & 2.59 \\
\hline Conflict Resolution & $37(21.3)$ & $17(9.8)$ & $100(57.4)$ & 20(11.5) & 451 & 2.59 \\
\hline Setting program priorities/decision making skills & $37(21.3)$ & 17(9.8) & $100(57.4)$ & 20(11.5) & 451 & 2.59 \\
\hline Group management & $39(22.4)$ & 17(9.8) & $100(57.4)$ & 18(10.3) & 445 & 2.56 \\
\hline Visualise future problems and prospect & $39(22.4)$ & 17(9.8) & $100(57.4)$ & 18(10.3) & 445 & 2.56 \\
\hline Group motivation & $50(28.7)$ & 20(11.5) & $80(45.9)$ & 24(13.8) & 426 & 2.45 \\
\hline Problem identification and solution & $50(28.7)$ & $20(11.5)$ & $80(45.9)$ & 24(13.8) & 426 & 2.45 \\
\hline
\end{tabular}

Source: Field survey, 2019

VII: Farmers' perception of extension workers' competency level in group facilitation

\begin{tabular}{lccc}
\hline \multicolumn{1}{c}{ Competence Level } & Frequency & Percentage & Mean \\
\hline Low $(<2.00)$ & 47 & 27.0 & \\
Fair $(2.00-2.99)$ & 72 & 41.4 & 2.36 \\
High $(\geq 3.00)$ & 55 & 31.6 & \\
\hline
\end{tabular}

Source: Field Survey, 2019 longer-serving workers were not readily adopting the changes in extension strategies over time while holding on to the traditional extension methods. On the contrary, the positive influence of access to training in group dynamics on the competence of extension workers in group facilitation implies that extension workers that attend more training had better competence level in group facilitation.

VIII: Determinants of field extension workers' competence level in group facilitation

\begin{tabular}{|c|c|c|c|c|}
\hline \multirow{2}{*}{ Socio-economic characteristics } & \multicolumn{2}{|c|}{ Unstandardized Coefficients } & \multirow{2}{*}{ t-value } & \multirow{2}{*}{ Sig. } \\
\hline & Beta & Std. Error & & \\
\hline Constant & 3.386 & 0.587 & 5.771 & 0.000 \\
\hline Sex & -0.051 & 0.054 & -0.954 & 0.344 \\
\hline Age & 0.056 & 0.054 & 1.047 & 0.299 \\
\hline Marital status & 0.109 & 0.129 & 0.848 & 0.399 \\
\hline Level of education & -0.138 & 0.222 & -0.624 & 0.535 \\
\hline Working experience & $-0.117^{* * *}$ & 0.036 & -3.242 & 0.002 \\
\hline Access to training in group dynamics & $0.214^{* * *}$ & 0.093 & 2.301 & 0.025 \\
\hline
\end{tabular}

Source: Field Survey, 2019; $\mathrm{R}=0.429,{ }^{* * *} \mathrm{P}<0.05, \mathrm{~F}=2.335$ 
IX: Result of the correlation analysis between the knowledge level of extension workers and level of competence in group facilitation

\begin{tabular}{lcc}
\hline & Knowledge Level & $\begin{array}{c}\text { Level } \\
\text { of Competence }\end{array}$ \\
\hline Knowledge Level & 1 & $0.843^{* * *}$ \\
Level of Competence & $0.843^{* * *}$ & 1 \\
\hline
\end{tabular}

Source: Field survey, 2019

***. Correlation is significant at 0.05 level (2-tailed)

\section{Relationship Between Knowledge Level of Extension Workers and Level of Competence in Group Facilitation}

Tab. IX shows the result of correlation analysis on the relationship between the knowledge level of extension officers and their competence in group facilitation.

The results reveal that at $r=0.843, p<0.05$, there was a significant positive relationship between knowledge and competence of extension officers in group facilitation. This implies that the higher the knowledge level of extension workers in group facilitation, the higher their competence in it. This means that field extension workers put their knowledge into action, and this was reflected in their competence level. It also implies that improvement of extension workers' knowledge will increase their competence.

\section{Comparison Between Field Extension Workers and Farmers' Rating of Extension Workers' Competence}

Tab. X shows the result of students' t-test analysis of the difference between the assessment of farmers and extension officers of their competence skills.

At $F=8.156, p<0.05$, there was a significant difference in the assessment of farmers and that of the extension officers on their competence in group facilitation. The rating of farmers was significantly lower than that from self-assessment by the field extension officers. Again, Sharma et al. (2016) stressed the disadvantage of weak objectivity associated with self-assessment. It is, however, important to note the striking similarities in the relative scores given to the various items used to measure competence by the two parties. Both farmers and the field workers rated about the same skills lowest.

$\mathrm{X}$ : Result of t-test showing the difference between the competences of extension officers as assessed by farmers the extension workers

\begin{tabular}{lcccccccc}
\hline & \multicolumn{2}{c}{ Levene's Test for Equality of Variances } & & \multicolumn{3}{c}{ t-test for Equality of Means } \\
\cline { 2 - 8 } & & F & Sig. & t & $\begin{array}{c}\text { Sig. } \\
\text { (2-tailed) }\end{array}$ & $\begin{array}{c}\text { Mean } \\
\text { Difference }\end{array}$ & $\begin{array}{c}\text { Std. Error } \\
\text { Difference }\end{array}$ \\
\hline Equal variances assumed & 8.156 & 0.005 & 2.376 & 0.018 & 0.086 & 0.036 \\
Equal variances not assumed & & & & 2.793 & 0.006 & 0.086 & 0.031 \\
\hline
\end{tabular}

Source: Field Survey, 2019

\section{CONCLUSION}

The study concluded that though field extension workers in Kwara State were highly informed on the importance of group facilitation as well as the qualities required for the task, they were not as well informed on the scope of group-facilitation. While they were highly competent in some aspects of group facilitation such as recording and reporting, leadership skills and communicating with farmers, they were not as competent in areas such as group motivation, group management, visualising future problems and prospect, problem identification and solution, selection/mobilisation of farmers group and feedback on programs. In addition, extension officers' work experience and exposure to training influenced their competence in group-facilitation. Based on the findings, the following recommendations will improve farmer-group facilitation.

Refresher extension training in group dynamics should be extended to long-serving extension workers to keep them revitalized.

Training programmes in group dynamics should focus on areas such as; group motivation, group management, visualising future problems and prospect, problem identification and solution, mobilisation of farmers group, feedback on programs and other areas where field extension officers show low competence.

Workshops on the scope of group facilitation should be organised for selected stakeholders such as farmers, field extension workers and extension supervisors to enhance their knowledge of the task. 


\section{REFERENCES}

ABARU, M. B., NYAKUNI, A., and SHONE, G. 2006. Strengthening farmers' organisations. The experience of RELMA and ULAMP. Working paper No. 23. Nairobi: World Agro forestry Centre.

BOSC, P. M., EYCHENE, D., HUSSEIN, K., LOSCH, B., MERCOIRRET, M. R., RONDOT, P. and MACKINOTOSCH-WALKER, S. 2002. The role of rural producer organisations in the World Bank rural development strategy. Rural Strategy Background Paper No. 8. Washington D. C: World Bank.

CHIKAIRE, J., U., EMERHIRHI, E., ANYOHA, N. P. and ONOH, P. A. 2018. Perceived competencies of agricultural extension advisory services providers in building rural farmer capabilities in Imo State, Nigeria. International Journal of Research in Agriculture and Forestry, 5(6): 25-32.

EJEMBI, E. P, OMOREGBEE, F. E. and EJEMBI, S. A. 2006. Farmers' assessment of the training and visit extension system in central Nigeria: Evidence from BarkinLadi, Plateau State. Journal of Social Sciences, 12(3): 207-212.

HERRINGER, J. M. 2002. Once isn't enough when measuring staff competence. Journal of Nursing Management, 33(2): 22-32.

ISSAHAKU, A. 2014. Perceived competencies of agricultural extension workers in extension service delivery in northern region of Ghana: Perspective from literature. Journal of Developing Country Studies, 4(15): 107-114.

MEENA, M. S., SINGH, K. M., MALIK, B. S., MEENA, B. S. and MANISH, K. 2012. Knowledge index for measuring knowledge and adopting scientific methods in treatment of reproductive problems of dairy animals. Journal of Agricultural Science, 4(10): 81-88.

MOORE, K. M. 2015. Confronting the challenge of Agricultural Education and Training. Presented at the MEAS Symposium on: Strengthening Extension and Advisory Services for Lasting Impacts Washington, D.C., 3-5 June 2015.

MUKINDIA, B. M. 2014. Influence of collective action on market access among smallholder banana farmers in Imenti South District, Kenya. International Journal of Social Sciences and Project Planning Management, 1(20): 99-110.

NWAOGU, F. K. and AKINBILE, L. A. 2018. Competencies of agricultural development programme personnel in extension service delivery in Oyo and Ogun States Nigeria. Journal of Agricultural Extension, 22(3): 40-52.

OMOTESHO, K. F., OGUNLADE, I., MUHAMMAD-LAWAL, A. and KEHINDE, F. B. 2016. Determinant of Level of Participation of Farmers in Group Activities in Kwara State, Nigeria. Journal of Agricultural Faculty of Gaziosmanpasa University, 33(3): 21-27.

OWEN, M. B. 2004. Defining key sub-competencies for administrative county leaders. Journal of Extension, 42(2): 2RIB3.

RAJALAHTI, R. 2012. Sourcebook overview and user guide. In: Agricultural innovation systems: An investment handbook. Washington D.C.: World Bank.

RAMDWAR, M. N., STOUTE, V. and GANPAT, W. G. 2015. Extension officers' perceptions of farmers' groups in Trinidad, West Indies and implications for extension. Journal of International Agriculture and Extension Education, 22(1): 35-48.

SHARMA, R., JAIN, A., GUPTA, N., GARG, S., BATTA, M. and DHIR, S. K. 2016. Impact of self-assessment by students on their Learning. International Journal of Applied and Basic Medical Research, 6(3): 226-229.

SUTTIE, D. bylo IFAD 2012. Rural poverty in developing countries: Issues, policies and challenges. International Fund for Agricultural Development. [Online]. Available at: https://www.un.org/ development/desa/dspd/wp-content/uploads/sites/22/2019/03/Rural-poverty-EGM_IFAD-overview. pdf [Accessed: 2020, January 22].

SUVEDI, M. and GHIMIRE, R. 2015. How competent are agricultural extension agents and extension educators in Nepal? [Online]. Available at: https://innovate.cired.vt.edu/wp-content/uploads/2015/09/ SuvediNepalExtensionFINAL.pdf [Accessed: 2020 March 03].

SWANSON, B. E., FARNER, B. J. and BAHAL, R. 1990. The current status of agricultural extension worldwide. In: SWANSON, B. E. (Ed.). Report of the Global Consultation on Agricultural Extension. Rome: Food and Agricultural Organisation of the United Nation (FAO), pp. 43-76.

Contact information

Kemi Funmilayo Omotesho: Omotesho.kf@unilorin.edu.ng

Blessing Akinola-Soji: blessingakins@gmail.com

Gbolagade Benjamin Adesiji: adesiji.g@unilorin.edu.ng

Oluwasanjo Biodun Owojaiye: sanjoowojaiye@gmail.com 
